\title{
Trakya bölgesi canavar otlarının (Orobanche cumana Wallr.) ayçiçeğinin gelişimi üzerine bazı etkilerinin belirlenmesi
}

\section{Determination of some effects of broomrapes (Orobanche cumana Wallr.) in Thrace region on the development of sunflower}

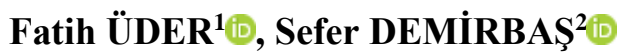 \\ ${ }^{1}$ Tekirdağ Namık Kemal Üniversitesi, Fen Bilimleri Enstitüsü, Tarımsal Biyoteknoloji Anabilim Dalı, 59030, Süleymanpaşa, Tekirdağ \\ ${ }^{2}$ Tekirdağ Namık Kemal Üniversitesi, Ziraat Fakültesi, Tarımsal Biyoteknoloji Bölümü, 59030, Süleymanpaşa, Tekirdağ \\ Sorumlu yazar (Corresponding author): S. Demirbaş, e-posta (e-mail): sdemirbas@nku.edu.tr \\ Yazar(lar) e-posta (Author e-mail): fatihuder@gmail.com
}

\section{MAKALE BİLGİSİ}

Alınış tarihi 17 Mayıs 2019

Düzeltilme tarihi 18 Haziran 2019

Kabul tarihi 27 Haziran 2019

\section{Anahtar Kelimeler:}

Orobanş

Bitki gelişimi

Spesifik yaprak alanı

Ayçiçeği

\begin{abstract}
ÖZ
Canavar otu (Orobanche cumana Wallr.) parazit bitkisi fotosentez yeteneğinden yoksun olmasından dolayı ayçiçeği (Helianthus annuus L.) üretim alanlarında enfeksiyon seviyesine bağlı olarak ciddi verim kayıplarına neden olmaktadır. Bu çalışmada, canavar otuna dayanıklı (LG5582) ve duyarlı (Özdemirbey) ayçiçeği çeşitlerinin 2003-2016 yılları arasında Tekirdağ, Kırklareli ve Edirne illerinin ayçiçeği üretimi yapılan bazı tarlalarından toplanmış canavar otu enfeksiyonundan ne derecede etkilendikleri belirlenmiștir. Öncelikle, toplanan canavar otu tohumlarının in vitro ortamda çimlenme kabiliyetleri belirlenmiştir. Sonrasında in vivo bitki yetiştirme ortamında canavar otu fidelerinin toprak yüzeyine çıktığı gün ayçiçeği bitkilerinden örneklemeler yapılarak kök/gövde uzunluğu, kök/gövde yaş ağırlığı, kök/gövde kuru ağırlığı, spesifik yaprak alanı (SLA) ve canavar otu enfeksiyon seviyesi belirlenmiştir. Elde edilen sonuçlara göre, duyarlı ayçiçeği çeșidinde en yüksek hasarın 2016 yılında toplanan canavar otu tohumlarından kaynaklandığı, 2003 yılında toplanan tohumlarının geçen süre zarfında hala çimlenebiliyor ve duyarlı ayçiçeği çeşidinde enfeksiyon yaratabiliyor olduğu, ayçiçeği bitkilerinin gelişimleri incelendiğinde enfeksiyon seviyesinde meydana gelen artışın kök uzunluğu, gövde yaş/kuru ağırlığında artışa SLA değerinde ise azalmaya neden olduğu. Ayçiçeği fidelerinin gövde uzunluğu ve kök yaş/kuru ağırlığında meydan gelen değişimlerin ise enfeksiyon ile ilişkilendirilemeyeceğini saptanmıştır.
\end{abstract}

\section{ARTICLE INFO}

Received 17 May 2019

Received in revised form 18 June 2019

Accepted 27 June 2019

\section{Keywords:}

Broomrape

Plant growth

Specific leaf area

Sunflower

\begin{abstract}
Broomrape parasitic plants (Orobanche cumana Wallr.) lack the ability of photosynthesis to cause severe yield losses due to infection level in sunflower (Helianthus annuus L.) production areas. In this study, it was tried to determine the extent to which broomrape resistant (LG5582) and sensitive (Özdemirbey) sunflower varieties were affected by broomrape infection collected from some fields of sunflower production in Tekirdağ, Kirklareli and Edirne provinces between 2003 and 2016. Firstly, germination ability of the collected broomrape seeds was determined in vitro condition. Then, the level of the broomrape infection and root/shoot length, fresh root/shoot weight, dry root/shoot weight, specific leaf area (SLA) was determined by the sampling of sunflower plants on the day of the broomrape seedlings' emerging the soil surface in vivo condition. According to the results, it was determined that the highest damage in sensitive sunflower variety was from the seeds of broomrape collected in 2016; the seeds collected in 2003 were still germinated and could cause infection in sensitive sunflower; the increase in infection level caused an increase in the root length and shoot weight/dry weight and a decrease in SLA level when the growth of sunflower plants were examined. And also, it was determined that changes in shoot length and root fresh/dry weight of sunflower seedlings could not be related to infection.
\end{abstract}




\section{Giriş}

Ayçiçeği (Helianthus annuus L.) Avrupa, ABD, Arjantin, Hindistan ve Çin'de yetiştirilebilen önemli bir yă bitkisidir (Prasad ve ark. 2017). FAO'nun 2017 yllı ayçiçeği üretim verileri incelendiğinde Dünya genelinde 27 milyon hektardan daha fazla tarım arazisinde üretim yapılırken ülkemizde bu alan yaklaşık 780 bin hektardır (FAO 2019). Rusya, Ukrayna, Bulgaristan, Türkiye, İspanya gibi ayçiçeği üretimi yapan ülkelerde verim ve kaliteyi etkileyen başlıca sınırlayıcı faktörlerden birisi olarak canavar otu (Orobanche spp.) parazit bitkisi kabul edilmektedir (Evci ve ark. 2011; Kaya 2014a). Fotosentez yapabilme kabiliyeti olmayan ve tam parazit bitkiler arasında yer alan ayçiçeği canavar otu bitkisi (Orobanche cumana Wallr.) konukçusunun su, mineral ve karbon kaynaklarını kullanarak bitkide hasara neden olur (Nickrent ve ark. 1998; Takagi ve ark. 2009). Yaşam döngüsünün büyük bir kısmını toprak altında geçiren canavar otlarının toprak üstüne çıktıktan kısa bir süre sonra oluşturduğu bitki başına yaklaşık 500.000 tohumun 15-20 y1l boyunca çimlenmeden toprak altında canlı kalabildiği bilinmektedir. Bu durum, canavar otuna karş1 yapılan mücadele yöntemlerinin önündeki en büyük engel olarak göze çarpmaktadır (Habimana ve ark. 2014). Mücadele yöntemlerin önündeki bir diğer engel ise $O$. cumana bitkisinin dayanıklı ayçiçeği çeşitlerine karşı geliştirmiş olduğu yeni ırk oluşturabilme potansiyelidir. Dünya genelinde toplam sekiz $O$. cumana irkının (A-H) olduğu (Velasco ve ark. 2007; Timko ve Scholes 2013), bunlardan F (Akhtouch ve ark. 2002), G ve H ırklarının en ciddi seviyede hasar oluşturduğu ifade edilmektedir (Kaya 2014a, 2014b; Molinero-Ruiz ve ark. 2015). Ülkemizde yayılış gösteren $O$. cumana bitkilerinin irkları hakkında literatürde bir bilgiye rastlanmasa da Tekirdağ, Kırklareli ve Edirne illerinden toplanan $O$. cumana bitkileri arasında genetik farklılığın olduğu belirlenmiş (Bilgen ve ark. 2019), ancak bu bitkilerin ayçiçeğinde yarattığı hasar hakkında bir bilgi bulunmamaktadır. Konukçu bitkilerde canavar otuna karşı dayanıklılık; kalloz ve süberin gibi bileşiklerin birikimi, konukçu hücre duvarında proteinlerin çapraz bağlanması, fenolik bileşiklerin birikimi, lignifikasyon ve nekrozlaşma, zehirli fitoaleksinlerin salgılanması ve antioksidan savunma sistemi ile ilişskilendirilmektedir (Goldwasser ve ark. 1999; Pérez-de-Luque ve ark. 2005; Demirbas ve Acar 2008, 2017; Yoder ve Scholes 2010).

Canavar otunun ayçiçeğinde meydana getirdiği enfeksiyon seviyesinin ayçiçeğinin büyüme ve gelişimini olumsuz yönde etkilediği ile ilgili birçok kaynak gösterilebilir. Bu çalışma, farklı yıllarda ve farklı bölgelerden toplanmış uygun depolama koşullarında saklanmış canavar otu tohumlarının duyarlı ve dayanıklı ayçiçeği çeşitlerinin gelişimi üzerindeki etkisinin gösterildiği, meydana gelen enfeksiyon seviyesi ile büyüme parametrelerindeki değişim arasındaki korelasyon ortaya konduğu ilk çalışmadır.

\section{Materyal ve Yöntem}

\subsection{Bitkisel Materyal}

Trakya bölgesinin farklı illerinden (Tekirdağ, Kırklareli, Edirne) farkl1 zamanlarda (2003-2016) toplanan (Çizelge 1) Orobanche cumana Wallr. bitkisine ait tohumlar ve canavar otuna dayanıklı (LG 5582) ve duyarlı (Özdemirbey) olduğu bilinen ayçiçeği tohumları kullanılmıştır.
Çizelge 1. O. cumana tohumlarının toplandığı bölgeler ve yıllar. Table 1. The regions and collected years of $O$. cumana seeds.

\begin{tabular}{lcc}
\hline Bölge & Toplanma Yılı & Kod \\
\hline 1 Lüleburgaz-Kırklareli & 2013 & LK2013 \\
$\mathbf{2}$ Sofuhalil-Kırklareli & 2013 & SK2013 \\
3 Avarız-Edirne & 2003 & AE2003 \\
$\mathbf{4}$ Sarıdanışment (Lalapaşa)-Edirne & 2013 & LE2013 \\
$\mathbf{5}$ Muratl1-Tekirdağ & 2013 & MT2013 \\
6 Hayrabolu-Tekirdağ & 2016 & HT2016 \\
\hline
\end{tabular}

\subsection{Canavar otu tohumlarının çimlenme kabiliyetlerinin belirlenmesi}

O. cumana tohumlarının Petri kaplarında çimlenme seviyelerinin belirlenmesi Demirbas ve ark. (2013)'e göre gerçekleştirilmiştir. Bir hafta süresince nemli ve $22 \pm 2^{\circ} \mathrm{C}$ ortamda stratifikasyon için bekleyen tohumlara çimlenebilmeleri için 1 ppm GR24 uygulanmıştır. Uygulamadan 6 gün sonra stereo mikroskop altında tohum sayımı yapılarak tohumların çimlenme oranları (\%) belirlenmiştir.

\subsection{Bitkilerin yetiştirilmesi ve örnekleme}

O. cumana bitkilerinin yetiştirilmesi için; her bir popülasyona ait $100 \mathrm{mg} O$. cumana tohumu perlit ve torf (1:1) içeren saksılara (1.5 l) eklenmiş ve tohumların saksıda homojen bir şekilde karışması sağlanmıştır. Ayçiçeği tohumları ise nemli kurutma kâğıdı içeren Petri kaplarında çimlendirilmiş ve 3 günlük fideler önceden hazırlanan saksılara, her bir saksıda 3 adet ayçiçeği fidesi olacak şekilde aktarılmıştır. Bitkiler bitki büyütme odasında $25 \pm 2^{\circ} \mathrm{C}$ sicaklıkta, 16 saat fotoperiyotta, 36 gün süresince yetiştirilmiştir. Bitkiler herhangi bir gübreleme işlemi yapılmaksızın haftada bir kez sulanmıştır. Ayçiçeği bitkilerinden canavar otlarının toprak yüzeyine çıktığ 136 . günde kök, gövde ve yaprak örneklemesi gerçekleştirilmiştir.

\subsection{Canavar otu enfeksiyon seviyesinin belirlenmesi}

Ayçiçeğinde meydana gelen enfeksiyon seviyesi, ayçiçeği köklerine yapışan canavar otu fidelerinin toprağa çıtığı gün sonlandırılmış (36. gün) ve her gruptan 5 ayçiçeği fidesinin kökleri kontrol edilerek bitki başına düşen canavar otu fidesi (Şekil 1) sayılarak belirlenmiştir.

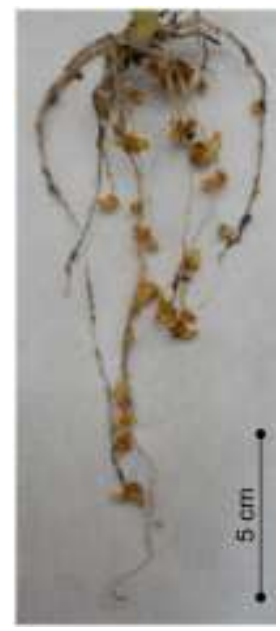

Şekil 1. Ayçiçeği köklerine yapışan canavar otu fideleri.

Figure 1. Broomrape seedlings penetrating to sunflower roots. 


\subsection{Ayçiçeği fidelerine ait büyüme parametreleri}

Ayçiçeği bitkilerinin kök ve gövde uzunluğu kök tacı ile yapraklarının en uç noktası arasındaki mesafe ölçülmüştür $(\mathrm{cm})$. Kök ve gövde yaş ağırlığı için fideler kök tacından kesilerek terazide tartılarak yaş ağırlıkları belirlendikten sonra kuru ağırlık değerlerinin belirlenmesi için bitkilerin kök ve gövde kısımları $70^{\circ} \mathrm{C}$ 'ye ayarlanmış etüvde 48 saat kurutulduktan sonra ağırlıkları hassas terazide (g) belirlenmiştir.

\subsection{Spesifik yaprak alanı (SLA)}

Spesifik yaprak alanı için ayçiçeği fidelerinin alttan ikinci yaprakları kullanılmıştır. Bu yaprakların fotoğrafları çekildikten sonra 48 saat $70{ }^{\circ} \mathrm{C}$ 'de etüvde kurutulmuş ve hassas terazide (mg) tartılmışlardır. Yaprak fotoğrafları Image J görüntü işleme programı kullanılarak yaprak yüzey alanı $\mathrm{cm}^{2}$ olarak belirlenmiştir. Spesifik yaprak alanı ise $\mathrm{cm}^{2} \mathrm{mg}^{-1}$ olarak ifade edilmiştir (Wilson ve ark. 1999).

\subsection{Istatistiksel analiz}

$\mathrm{Bu}$ çalışma, tesadüf parsellerinde bölünmüş parseller deneme desenine göre 3 tekrarlı olarak kurulmuştur. Elde edilen veriler tek yönlü varyans analizi (One Way Anova) ile SPSS 18 paket programı ile incelenmiştir. Ortalama değerler arasındaki farkların istatistiki önemlilikleri $\mathrm{P} \leq 0.05$ düzeyinde LSD (Least Significant Difference-En Küçük Önemli Fark) testi ile belirlenmiştir. Enfeksiyon seviyesi ve her bir büyüme parametresi arasında doğrusal bir ilişkinin olup olmadığını belirlenmek için Pearson korelasyon analizi yapılmıştır. Korelasyon katsayıları değerlendirilerek iki değişken arasında ters veya doğru orantılı bir ilişki olup olmadığı saptanmıştır.

\section{Bulgular}

Ayçiçeği fidelerinde meydana gelen enfeksiyon seviyesinin belirlenmesinden önce farklı zaman ve farklı bölgelerden toplanan canavar otu tohumlarının çimlenme kabiliyetleri belirlenmiştir. Petri kabında yapılan çalışmada, AE2003, MT2013, LK2013, HT2016 ve LE2013 bölgelerinden toplanan canavar otu tohumlarının çimlenme seviyeleri sırasıyla \%15.5; \%46.0; \%58.3; \%58.9 ve \%71.2 olarak belirlenmiştir. SK2013 bölgesinden toplanan tohumlarda ise çimlenme gözlenmemiştir (Çizelge 2).

Canavar otu fidelerinin toprak yüzeyine çıktığı anda canavar otlarının duyarlı ve dayanıklı ayçiçeğinde yaratmış olduğu enfeksiyon seviyesinde ve ayçiçeği bitkilerinin gelişiminde farklı düzeyde değişimler meydana gelmiştir. Dayanıklı olan çeşitte farklı bölgelerden toplanan canavar otu tohumlarının hiçbirinin ayçiçeğinde enfeksiyon yaratmamasına karşın,
SK2013 grubu hariç diğer bölgelerden toplanan tohumların duyarlı çeşitte enfeksiyon yarattığ 1 ve en yüksek enfeksiyonun HT2016 grubunda \%32.4 oranında meydana geldiği saptanmıştır. Enfeksiyon seviyesi sıralaması yapıldığında yüksekten düşüğe doğru LE2013 (18.2), LK2013 (11.0), MT2013 (11.0) ve AE2003 (7.6) şeklinde bir sıralama olduğu belirlenmiştir (Çizelge 3).

Canavar otu enfeksiyonunun kontrol bitkilerine kıyasla ortalama kök uzunluğunda duyarlı çeşitte \%6.29; dayanıklı çeşitte ise \%4.54 oranında bir azalmaya neden olmasına rağmen bu azalmaların istatistiksel olarak anlamlı olmadığ belirlenmiştir (Şekil 2.a).

Her iki çeşidin gövde uzunluğunun kontrole oranla tüm gruplarda azaldığı, en yüksek seviyedeki azalmanın duyarlı çeşitte \%13.31 oranı ile HT2016'da azaldığı, dayanıklı çeşitte ise en yüksek baskının LE2013'de \%16.97 oranında olduğu belirlenmiştir. Canavar otu enfeksiyonunun tüm bölge ortalamaları değerlendirildiğinde ise gövde uzunluğunun kontrole oranla duyarlı çeşitte $\% 6.93$ dayanıklı çeşitte $\% 11.69$ oranında azaldığı belirlenmiştir (Şekil 2.b).

Kök yaş ağırlığının kontrole oranla her iki çeşitte de azaldığı, bu azalmanın duyarlı çeşitte LK2013'de \%77.01 oranında dayanıklı çeşitte AE2003'de \%80.39 oranında olduğu belirlenmiştir. Canavar otu enfeksiyonunun tüm bölge ortalamaları değerlendirildiğinde kök yaş ağırlığının kontrole oranla duyarlı çeşitte $\% 57.70$ dayanıklı çeşitte ise $\% 54.78$ oranında azaldığı belirlenmiştir (Şekil 2.c).

Duyarlı çeşidin gövde yaş ağırlığının kontrole oranla LE2013 ve MT2013'de sirasiyla \%5 ve \%43.02 artmasina rağmen AE2003, HT2016 ve LK2013'de sirasiyla \%17.85, $\% 18.91$ ve $\% 27.85$ azaldığı dayanıklı çeşitte ise HT2016 ve MT2013'de sirasiyla \%17.08 ve \%18.52 arttı̆̆1, AE2003, LK2013 ve LE2013'de ise sirasiyla \%14.84, \%31.67 ve \%51.22 oranında azaldığı belirlenmiştir. Canavar otu enfeksiyonunun tüm bölge ortalamaları değerlendirildiğinde gövde yaş ağırlığının kontrole oranla duyarlı çeşitte \%3.32 dayanıklı çeşitte ise \%12.43 oranında azaldığı belirlenmiştir (Şekil 2.d).

Her iki ayçiçeği çeşidinin kök kuru ağırlığının kontrole oranla MT2013 hariç diğer gruplarda azaldığ $1, \% 70$ 'in üzerinde azalmanın HT2016, LK2013 ve AE2003 gruplarında olduğu belirlenmiştir. Canavar otu enfeksiyonunun tüm bölge ortalamaları değerlendirildiğinde kök kuru ağırlığının kontrole oranla her iki çeşitte de \%50'nin üzerinde azalma yarattığı belirlenmiştir (Şekil 2.e).

Duyarlı çeşidinin gövde kuru ağırlığının kontrole oranla MT2013'de \%49.85 arttı̆g diğer gruplarda ise azalma olduğu belirlenmiştir. Dayanıklı çeşidin ise düşükte olsa HT2016'de

Çizelge 2. Farklı bölgelere ait canavar otu tohumlarının çimlenme seviyeleri (\%).

Table 2. Germination levels (\%) of broomrape seeds belonged different regions.

\begin{tabular}{lllllll}
\hline & SK2013 & AE2003 & MT2013 & LK2013 & LE2013 & HT2016 \\
\hline Çimlenme (\%) & $0 \pm 0.00 \mathrm{a}$ & $15.5 \pm 0.70 \mathrm{~b}$ & $46.0 \pm 1.59 \mathrm{c}$ & $58.3 \pm 3.15 \mathrm{~d}$ & $71.2 \pm 3.22 \mathrm{e}$ & $58.9 \pm 4.32 \mathrm{~d}$ \\
\hline
\end{tabular}

Sonuçlar ortalama \pm std hata şeklinde verilmiştir.

Results are given as mean \pm std error.

Çizelge 3. Canavar otu enfeksiyon seviyesi (adet / ayçiçeği).

Table 3. Broomrape infection level (number / sunflower).

\begin{tabular}{|c|c|c|c|c|c|c|}
\hline & SK2013 & AE2003 & MT2013 & LK2013 & LE2013 & HT2016 \\
\hline Enfeksiyon seviyesi (adet/ayçiçeği) & $0 \pm 0.00 \mathrm{a}$ & $7.6 \pm 2.16 \mathrm{ab}$ & $11.0 \pm 1.58 \mathrm{ab}$ & $11.0 \pm 2.17 \mathrm{ab}$ & $18.2 \pm 1.93 b$ & $32.4 \pm 6.89 \mathrm{c}$ \\
\hline
\end{tabular}

Sonuçlar ortalama \pm std hata seklinde verilmiștir. Sonuçların yanındaki harfler (a-c) ortalamalar arasındaki anlamlılık düzeyini ifade etmektedir.

Results are given as mean \pm std error. The letters next to the results $(\mathrm{a}-\mathrm{c})$ mean the level of significance between the averages. 
arttığı diğer gruplarda azaldığı belirlenmiş̧tir. Canavar otu enfeksiyonunun tüm bölge ortalamaları değerlendirildiğinde her iki çeşitte de yaklaşık \%25 oranında gövde kuru ağırlığının azaldığı belirlenmiştir (Şekil 2.f).

Duyarlı ve dayanıklı çeşidin SLA değerinde meydana gelen değişimler incelendiğinde, kontrole oranla tüm gruplarda artış olduğu belirlenmiştir. En yüksek artış duyarlı

çeşit için LK2013'de \%64.10 oranında olduğu dayanıklı çeşitte ise bu oran AE2003'de \%45.47 olduğu belirlenmiştir. Canavar otu enfeksiyonunun tüm grup ortalamaları kıyaslandığında duyarlı çeşitte \%51.79 oranında, dayanıklı çeşitte ise \%31.72 oranında artış olduğu belirlenmiştir (Şekil 2.g).
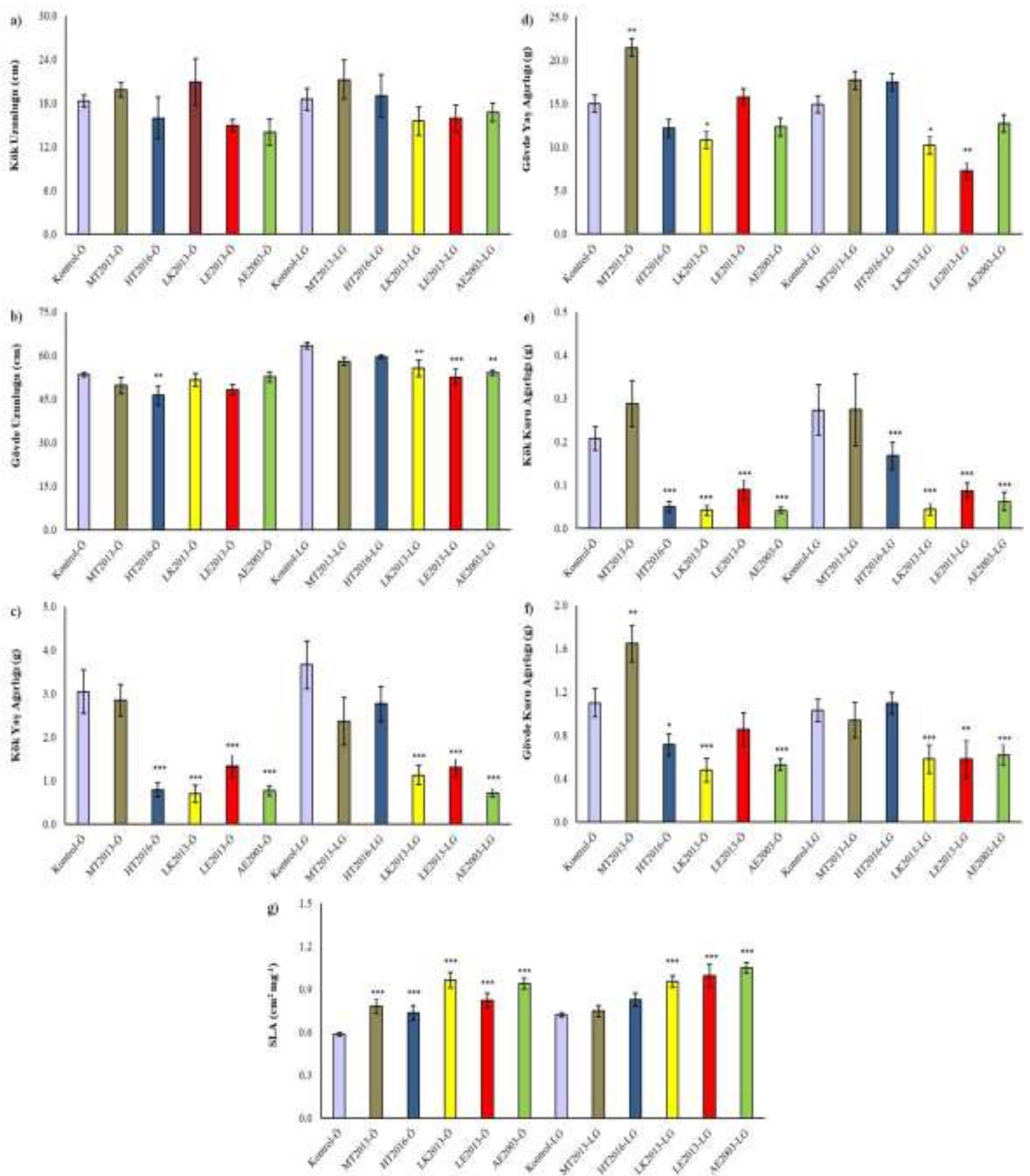

Sekil 2. Farklı bölgelere ait canavar otlarının duyarlı (Özdemirbey) ve dayanıklı (LG5582) ayçiçeği çeșitlerinin (a) kök ve (b) gövde uzunluğu (cm), (c) kök ve (d) gövde yaş ağırlı̆̆ı (g), (e) kök ve (f) gövde kuru ağırlığı (g) ile (g) SLA değerinde $\left(\mathrm{cm}^{2} \mathrm{mg}^{-1}\right)$ meydana getirdiği değişimler. Her iki çeşit kendi kontrol bitkilerine göre değerlendirilmiş ve sütunlar üzerinde bulunan yıldızlar istatistiksel olarak önemlilik düzeyini ifade etmektedir (*: $\mathrm{P} \leq 0.05 ; * *: \mathrm{P} \leq 0.01 ; * * *: \mathrm{P} \leq 0.001)$

Figure 2. Sensitive (Özdemirbey) and resistant (LG5582) sunflower varieties belonging to different regions (a) root and (b) shoot length (cm), (c) root and (d) shoot weight $(\mathrm{g})$, (e) and (f) shoot dry weight $(\mathrm{g})$ and $(\mathrm{g})$ changes in SLA value $\left(\mathrm{cm}^{2} \mathrm{mg}^{-1}\right)$. Both varieties were evaluated according to their control plants and the stars on the columns were statistically significant $(*: \mathrm{P} \leq 0.05 ; * *: \mathrm{P} \leq 0.01 ; * * *: \mathrm{P} \leq 0.001)$. 
Canavar otu enfeksiyon seviyesinde meydana gelen artışının kök uzunluğu (Şekil 3.a), gövde yaş (Şekil 3.b) ve kuru ağırlığını (Şekil 3.c) arttırdığı belirlenmiştir. Canavar otu enfeksiyon seviyesi ile artış gösteren parametreler arasındaki ilişki Pearson korelasyon katsayı modeline göre, kök uzunluğu $\left(\mathrm{R}^{2}\right.$ : 0.1516) ve gövde yaş ağırlığı $\left(\mathrm{R}^{2}: 0.1306\right)$ ile zayıf, gövde kuru ağırlığı $\left(\mathrm{R}^{2}\right.$ : 0.0755$)$ ile çok zayıf düzeyde olduğu belirlenmiştir (Şekil 3).
Canavar otu enfeksiyon seviyesi arttıkça SLA değerinde azalmanın meydana geldiği, enfeksiyon seviyesi ile ilişkisi değerlendirildiğinde Pearson korelasyon katsayı modeline göre, SLA $\left(\mathrm{R}^{2}: 0.7\right)$ ile arasındaki ilişkinin yüksek seviyede olduğu belirlenmiştir (Şekil 4).
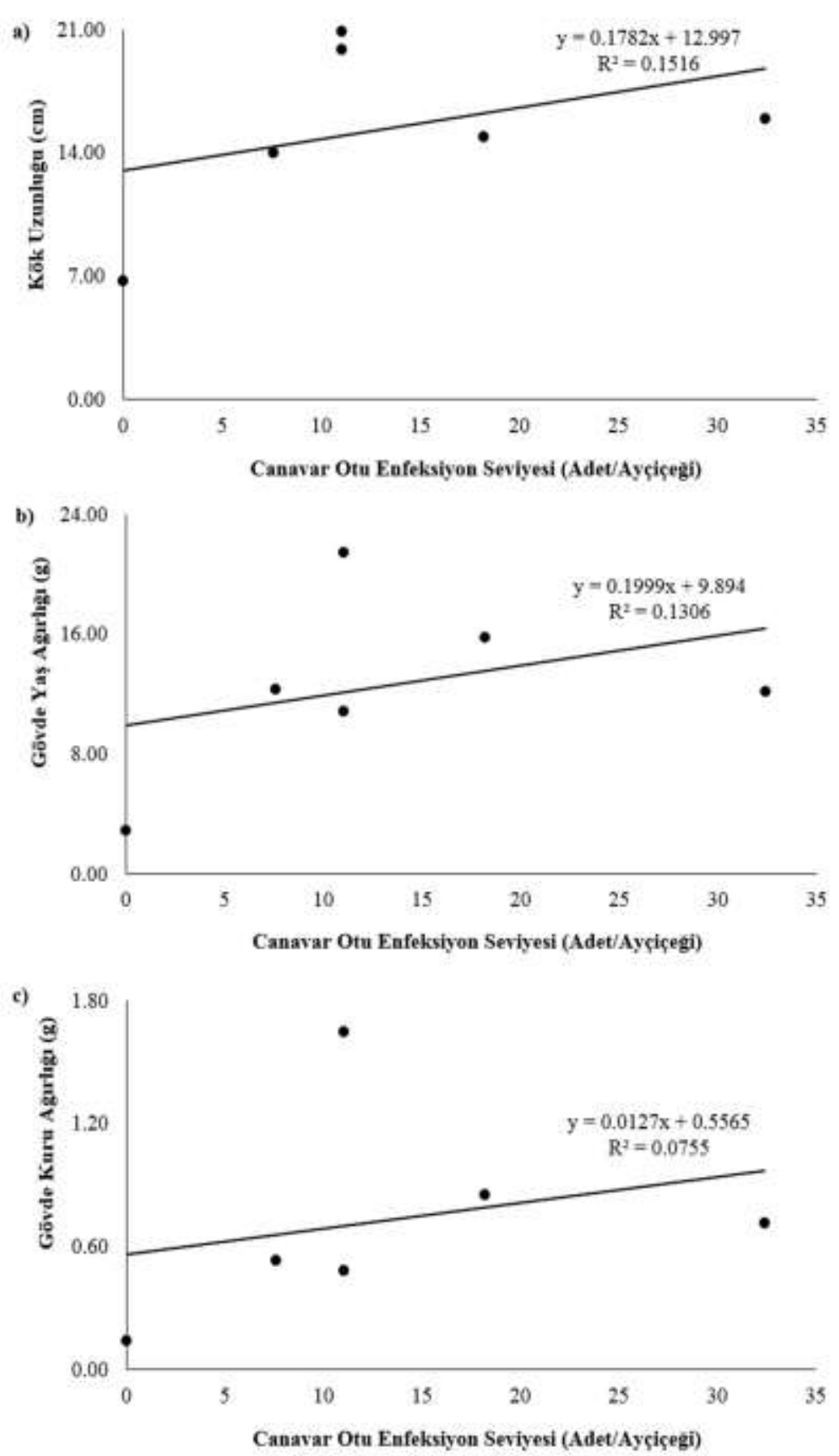

Şekil 3. Canavar otu enfeksiyon seviyesi ile artış gösteren parametreler (a) kök uzunluğu (b) gövde yaş (c) gövde kuru ağırlığı. Figure 3. Parameters showing increases with the level of broomrape infection (a) root length (b) shoot wet (c) dry weight. 


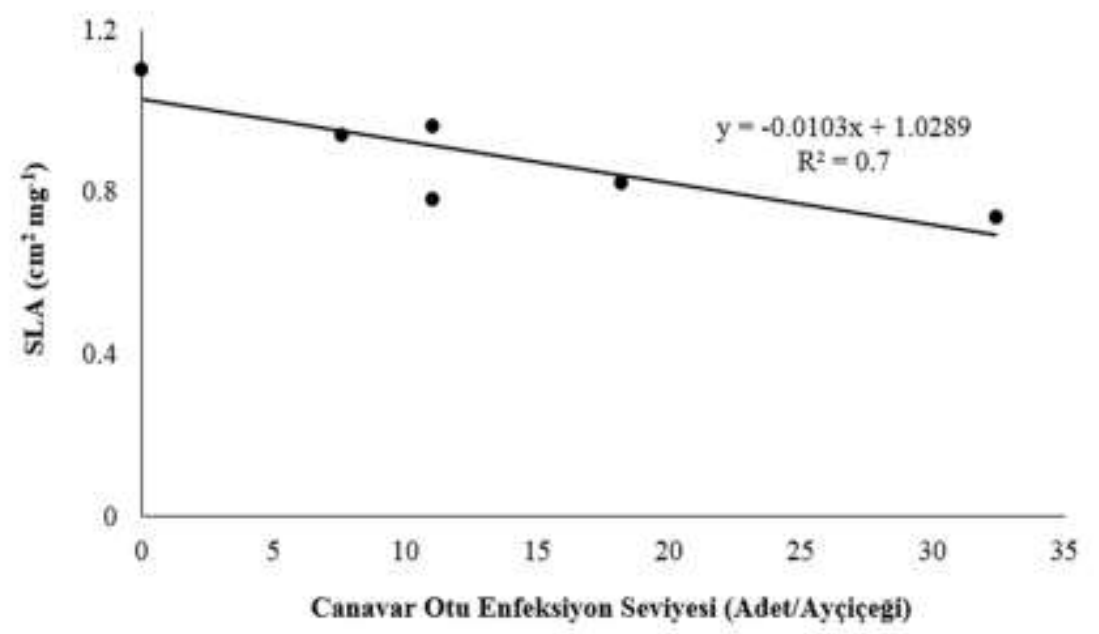

Şekil 4. Canavar otu enfeksiyon seviyesi ile SLA değeri arasındaki ilişki.

Figure 4. Relationship between broomrape infection level and SLA value.

\section{Tartışma ve Sonuç}

Canavar otu türlerinin konukçusu olduğu bitkilerin büyümesine baskılayıcı etkisinin olduğu bilinmesine rağmen (Barker ve ark. 1996; Dale ve Press 1998; Lins ve ark. 2007; Demirbas ve Acar 2008, 2017; Yang ve ark. 2017), Trakya'nın farklı illerinden (Tekirdağ, Kırklareli, Edirne) farklı zamanlarda (2003-2016) toplanan canavar otu tohumlarının duyarlı ve dayanıklı ayçiçeği çeşitlerinde neden olduğu enfeksiyon seviyesi ve büyüme parametreleri arasındaki ilişki ilk kez bu çalışma ile ortaya konmuştur. Elde edilen sonuçlara bakıldığında, duyarlı ayçiçeği çeşidinde en yüksek hasar yaratan grubun HT2016 olması, toplanma y1lı da dikkate alındığında bu bölgeden toplanmış olan canavar otlarının yeni bir 1 rk olabileceğini düşündürmektedir. 2003 y1lında toplanan AE2003 grubu canavar otu tohumlarının geçen süre zarfinda hala çimlenebiliyor ve duyarlı ayçiçeği çeşidinde enfeksiyon yaratabiliyor olması da bir diğer önemli bulgudur. Canavar otu enfeksiyonu altında ayçiçeği bitkilerinin gelişimleri incelendiğinde enfeksiyon seviyesinde meydana gelen artışın kök uzunluğu, gövde yaş/kuru ağırlığında artışa neden olmakla beraber, SLA değerini azalttığı saptanmıştır. Ayçiçeği fidelerinin gövde uzunluğu ve kök yaş/kuru ağırlığında meydan gelen değişimlerin ise enfeksiyon ile ilişkilendirilemeyeceğini ortaya koymuştur. Sonuç olarak, ülkemiz için önemli bir endüstri bitkisi olan ayçiçeğinin, canavar otu gibi dayanıklılık mekanizmasını yeni oluşturduğu ırklarla aşabilen parazit bitkilere karşı daha dayanıklı ayçiçeği çeşitlerinin geliştirildiği 1slah çalışmalarında fizyolojik parametrelerin daha etkin olarak kullanılması çalışmalara katkı sağlayacaktır.

\section{Teșekkür}

Özdemirbey çeşidine ait ayçiçeği tohumları ve farklı bölgelerden toplanan canavar otu tohumlarının sağlanmasındaki yardımlarından dolayı Trakya Tarımsal Araştırma Enstitüsünden Dr. Göksel EVCI'ye teşekkür ederiz.

\section{Kaynaklar}

Akhtouch B, Muñoz-Ruz J, Melero-Vara J, Fernández-Martínez J, Domínguez J (2002) Inheritance of resistance to race $F$ of broomrape in sunflower lines of different origins. Plant Breeding 121(3): 266-268.
Barker ER, Press MC, Scholes JD, Quick WP (1996) Interactions between the parasitic angiosperm Orobanche aegyptiaca and its tomato host: growth and biomass allocation. New Phytol 133: 637642 .

Bilgen BB, Barut AK, Demirbaş S (2019) Genetic characterization of Orobanche cumana populations from the thrace region of Turkey using microsatellite markers. Turkish Journal of Botany 43(1): 3847.

Dale H, Press MC (1998) Elevated atmospheric $\mathrm{CO}_{2}$ influences the interaction between the parasitic angiosperm Orobanche minor and its host Trifolium repens. New Phytol 140: 65-73.

Demirbas S, Acar O (2008) Superoxide dismutase and peroxidase activities from antioxidative enzymes in Helianthus annuus L. roots during Orobanche cumana Wallr. penetration. Fresenius Environmental Bulletin 17(8a): 1038-1044.

Demirbas S, Vlachonasios KE, Acar O, Kaldis A (2013) The effect of salt stress on Arabidopsis thaliana and Phelipanche ramosa interaction. Weed Research 53(6): 452-460.

Demirbas S, Acar O (2017) Physiological and biochemical defense reactions of Arabidopsis thaliana to Phelipanche ramosa infection and salt stress. Fresenius Environmental Bulletin 26(3): 2268-2275.

Evci G, Sezer N, Pekcan V, Yilmaz MI, Kaya Y (2011) Broomrape control in sunflower production in Turkey. Basic Articles 314: 111117.

FAO (2019) http://www.fao.org/faostat/en/\#data/QC. Erişim 10 Ocak 2019.

Goldwasser Y, Hershenhorn J, Plakhine D, Kleifeld Y, Rubin B (1999) Biochemical factors involved in vetch resistance to Orobanche aegyptiaca. Physiological and Molecular Plant Pathology 54(3): 8796.

Habimana S, Nduwumuremyi A, Chinama RJD (2014) Management of Orobanche in field crops- A Review. Journal of Soil Science and Plant Nutrition 14(1): 43-62.

Kaya Y (2014a) Current situation of sunflower broomrape around the world. In: Current Situation of Sunflower Broomrape around the World, Proceedings of the Third International Symposium on Broomrape (Orobanche spp.) in Sunflower, 3-6 June, Cordoba, Spain. Paris, France: International Sunflower Association, pp. 9-18.

Kaya Y (2014b) The situation of broomrape infestation, control methods in sunflower production areas in Turkey. In: Current Situation of Sunflower Broomrape around the World, Proceedings of the Third International Symposium on Broomrape (Orobanche spp.) in Sunflower, 3-6 June, Cordoba, Spain. Paris, France: International Sunflower Association, pp. 55. 
Lins RD, Colquhoun JB, Mallory-Smith CA (2007) Effect of small broomrape (Orobanche minor) on red clover growth and dry matter partitioning. Weed Sci. 55: 517-520.

Molinero-Ruiz L, Delavault P, Perez-Vich B, Pacureanu-Joita M, Bulos M, Altieri E, Dominguez J (2015) History of the race structure of Orobanche cumana and the breeding of sunflower for resistance to this parasitic weed: a review. Span J Agric Res. 13: 4.

Nickrent DL, Duff JR, Colwell AE, Wolfe AD, Young ND, Steiner KE, dePamphilis CW (1998) Molecular phylogenetic and evolutionary studies of parasitic plants. Molecular Systematics of Plants II DNA Sequencing, Ed: Soltis DE, Soltis PS, Doyle JJ, Springer Science Business Media, New York, ABD, pp. 211-241.

Pérez-de-Luque A, Jorrín J, Cubero JI, Rubiales D (2005) Orobanche crenata resistance and avoidance in pea (Pisum spp.) operate at different developmental stages of the parasite. Weed Research 45(5): 379-387.

Prasad MSL, Sujatha M, Alivelu K, Sujatha K (2017) Sources of resistance to Alternariaster leaf blight in sunflower pre-breeding lines derived from interspecific crosses and wild Helianthus species. Crop Protection 92: 70-78.

Takagi K, Okazawa A, Wada Y, Mongkolchaiyaphruek A, Fukusaki E, Yoneyama K, Takeuchi Y, Kobayashi A (2009) Unique phytochrome responses of the holoparasitic plant Orobanche minor. New Phytologist 182(4): 965-74.
Timko MP, Scholes JD (2013) Host reaction to attack by root parasitic plants. In: Joel DM, Gressel J, Musselman LJ, editors. Parasitic Orobanchaceae. New York, NY, USA: Springer, pp. 115-141.

Velasco L, Perez-Vich B, Jan CC, Fernandez-Martinez JM (2007) Inheritance of resistance to broomrape (Orobanche cumana Wallr.) race $\mathrm{F}$ in sunflower line derived from wild sunflower species. Plant Breeding 126: 67-71.

Wilson PJ, Thompson KEN, Hodgson JG (1999) Specific leaf area and leaf dry matter content as alternative predictors of plant strategies. The New Phytologist 143(1): 155-162.

Yang C, Xu L, Zhang N, Islam F, Song W, Hu L, Zhou W (2017) iTRAQ-based proteomics of sunflower cultivars differing in resistance to parasitic weed Orobanche cumana. Proteomics 17(1314): $13-14$.

Yoder JI, Scholes JD (2010) Host plant resistance to parasitic weeds; recent progress and bottlenecks. Current Opinion in Plant Biology 13: $478-484$. 